\title{
RESPONDEO ERGO SUM : BELAJAR TANGGUNG JAWAB DARI LEVINAS
}

\author{
Elfi \\ e-Mail : elfitajudin@gmail.com \\ UIN Imam Bonjol Padang
}

\begin{abstract}
Abstrak: Masalah utama dalam tulisan ini adalah relasi antar sesama manusia seharusnya didasari oleh suatu tanggungjawab bukan sekedar kewajiban etis saja. Karena tanggung jawab dapat menjadi dasar bagi pertanggungjawaban kepada Tuhan. Untuk mewujudkan ini Levinas berangkat dari analisisnya tentang peranan subjek yang bersifat totalitas. Semuanya harus ditentukan subjek. Padahal sesungguhnya, objek yang selama ini terabaikan dapat membuat subjek menjadi ada. Subjek ditentukan objek. Objek membuat subjek menjadi ada, objek membuat subjek bertanggung jawab. Hasilnya, Levinas mampu mengangkat posisi objek yang terabaikan itu menjadi sentral. Objek itu adalah yang lain selain subjek. objek bisa berbentuk manusia atau lainnya. Namun yang dimaksud objek di sini adalah manusia, orang lain, wajah dalam keberlainannya.
\end{abstract}

Kata kunci : Tanggung Jawab

\section{PENDAHULUAN}

Dalam hidup sehari-hari, orang sering mengabaikan hal sekelilingnya. Dia tidak acuh, bahkan terkesan cuek pada keadaan dan kejadian sekitarnya. Dia mengabaikan keberadaan orang lain sehingga terkesan orang lain itulah yang harus memahami dan menyesuaikan diri dengan dia. Biasanya, setelah terjadi barulah dia terkejut dan selanjutnya bertanyatanya; apa yang terjadi?

Dirunut $\begin{gathered}\text { dari } \\ \text { filsafat }\end{gathered} \begin{array}{r}\text { sejarah } \\ \text { barat, }\end{array}$
perkembangan
penekanan pada subjek (aku, ego)
sesungguhnya sudah berakar dari
filsafat Rene Descartes (1596-1650).
Ungkapan cogito ergo sum (saya
berfikir maka saya ada) membawa
konsekuensi besar bagi perkembangan
filsafat sesudahnya. Rasio ditempatkan
pada posisi tertinggi kehidupan.

Akibatnya, subjek menjadi penentu dalam semua hal. Semuanya ditentukan dan bahkan harus menyesuaikan diri dengan aku, subjek.

Keberadaan filsafat yang ingin membangun keseluruhan yang berpangkal pada "aku, ego, subjek", melahirkan filsafat yang bersifat totalitas. Keberadaan objek (dunia luar) menjadi tidak menentukan lagi karena semuanya telah ditentukan atau harus menyesuaikan diri dengan subjek. Dunia luar menjadi tidak mandiri bahkan obyek pengertian sesungguhnya adalah hasil rekayasa akal sendiri. Pandangan seperti ini telah berlangsung selama berabad-abad dan hampir selalu luput dari perhatian para filosof.

Terjadinya Perang Dunia I (1914-1918) dan Perang Dunia II (1939-1945) mengakibatkan kerusakan 
dan kehancuran di mana-mana. Akibatnya nyawa manusia menjadi tidak berharga sama sekali. Usaha untuk mengangkat dan menghidupkan kembali nilai manusia ini sudah pernah dilakukan oleh aliran eksistensialisme. Namun usahanya gagal mengangkat posisi objek. Eksistensialisme masih sama dengan aliran terdahulu, subjek tetap dominan dan totalitas.

Kurangnya perhatian kepada objek inilah yang pada akhirnya mendorong salah seorang filosof barat kontemporer bernama Emmanuel Levinas (1906-1995) untuk berusaha mendobrak dominasi subjek tersebut dengan memberikan perhatian lebih terhadap peranan objek dalam kehidupan. Bagi Levinas, keadaannya bukanlah demikian. Justru kehadiran dan keberadaan objek, orang lain, atau dunia luar, yang membuat manusia menjadi ada.

\section{SIAPA ITU LEVINAS?}

Nama lengkapnya adalah Emmanuel Levinas, lahir tahun 1906 di Kaunas, Lithuania, dari keluarga keturunan Yahudi. Pendidikan dasar hingga menengah diselesaikan di Kaunas, sedangkan pendidikan tinggi ditempuhnya di Perancis. Tahun 19281929, Levinas belajar langsung dengan dua filososf besar, Edmund Husserl (1859-1938) dan Martin Heidegger (1889-1976) selama dua semester di Freiburg, Jerman dan menyaksikan langsung sukses besar pemikiran kedua filosof besar tersebut. Tahun 1930 Levinas memperoleh gelar
Doktor dari Universitas Sorbonne, dengan disertasi "La Theorie de L'instuion dans la Phenomenologie de Husserl" (Teori tentang Intuisi dalam Fenomenologi Husserl”. Menurut kesaksian Levinas, ia sangat terkesan dengan suasana intelektual dan kultural Perancis waktu itu sehingga orang dapat melekat pada bangsa ini dengan hati dan budi sama seperti karena asalusul" (K. Bertens, 2006:309). Tahun 1939 Levinas masuk dinas militer dan sempat menjadi tawanan perang Jerman hingga tahun 1945. Namun ia luput dari peristiwa pembunuhan besarbesaran oleh Nazi karena keturunan Yahudinya tidak diketahui, tapi seluruh keluarganya di Kaunas tidak selamat. Peristiwa ini sangat berbekas dan memberi pengaruh besar dalam kehidupannya. Setelah bebas ia kembali dan menetap Perancis dengan menghabiskan hidupnya di bidang akademis sampai ia meninggal dunia tanggal 25 Desember 1905.

Karya Levinas sangat banyak baik berupa terjemahan atau berupa karya asli. Namun karya monumental dan membuat ia terkenal adalah Totalite et Infini (Totalitas dan Tak Berhingga) yang terbit tahun 1961 dan Autrement qu'etre ou au-dela de (Lain daripada Ada atau di Seberang Esensi) terbit tahun 1974.

Ada tiga sumber utama pemikiran Levinas yaitu tradisi Yahudi, sejarah filsafat barat dan metode pendekatan fenomenologis. Pertama, tradisi Yahudi. Sebagaimana disebutkan di atas Levinas berasal dari 
keturunan Yahudi yang taat, yang menurut kesaksiannya sendiri, ia dibesarkan dengan kitab Ibrani. Ia hidup dalam zaman yang menyaksikan pembaruan semangat religius Yahudi abad 20 yang dimotori dua filsuf Yahudi, Martin Buber dan Franz Rosenzweig. Dua filsuf Yahudi ini memainkan peranan penting dalam gerakan pembaruan tersebut. Terutama buku Rosenzweig "Bintang Penebusan" sangat mendalam mempengaruhi Levinas. Disebutkan sendiri dalam awal karyanya "Totalitas dan Tak Berhingga", karya Rosenzweig "Bintang Penebusan" tidak dikutip eksplisit olehnya tetapi kehadirannya terasa dalam seluruh buku (K. Bertens, 2006:315). Di samping itu, penderitaan yang dialami orang Yahudi yang terusir di Eropa, khususnya di Jerman tahun 1930-an, juga menginspirasi pemikirannya sehingga ia membangun filsafatnya atas dasar tanggung jawab dan penghargaan atas orang lain dan sesama manusia.

Kedua, sejarah filsafat barat. Bagi Levinas filsafatnya adalah diskusi dengan seluruh sejarah filsafat Barat sejak Plato hingga Heidegger (K. Bertens, 2006:315). Dalam banyak hal terlihat bagaimana Levinas mengutip pemikiran filosof terdahulu dan mengomentarinya. Filsafat barat dapat diperbandingkan dengan kisah seorang pengembara Yunani bernama Odysseus yang telah lama berpetualang akhirnya kembali pulang ke kampung halamannya.
Ketiga, pendekatan fenomenologis. Telah disampaikan sebelumnya bahwa Levinas pernah belajar secara langsung dengan tokoh utama fenomenologi yakni Edmund Husserl dan Martin Heidegger. Dalam bukunya, "Totalitas dan Tak Berhingga", Levinas mengatakan bahwa ia sangat berhutang budi pada metode pendekatan fenomenologis" (K. Bertens, 2006:316). Namun demikian, Levinas tidak termasuk dalam arti fenomenologi tradisional tersebut. Menurut S. Strasser (Profesor Belanda), fenomenologi Levinas adalah suatu fenomenologi gaya baru. Levinas memperkaya pemikiran fenomenologi dengan membuka suatu dimensi baru (K. Bertens, 2006:316).

\section{SAYA BERTANGGUNG JAWAB KARENA ITU SAYA ADA}

Istilah respondeo ergo sum (saya bertanggung jawab maka saya ada) adalah istilah baru yang digunakan Levinas untuk mengganti istilah cogito ergo sum (saya berfikir maka saya ada) yang kumandangkan Rene Descartes. Levinas menilai bahwa selama ini filsafat barat hanya menekankan dominasi subjek saja. Subjek menjadi totalitas. Yang lain ditentukan oleh subjek. Dasar cogito adalah subjek. Sedangkan respondeo adalah tanggung jawab. Tanggung jawab menjadi ada karena ada orang lain, "wajah", yang tak terhingga di luar subjek. Jadi objek yang membuat subjek menjadi ada.

\section{Totalitas Subyek}


Dalam sistem filsafat barat (terutama sejak masa modern), secara menyolok diwarnai oleh diskursus (uraian sistematik) tentang Ego (Aku, Subjek) yang selalu berakhir pada bentuk pengabstraksian realitas menjadi representative universal. Subjek dipahami sebagai pelaku yang berfikir yang menjadi pendukung atau penyebab peristiwa-peristiwa mental (Lorens Bagus, 1996:1045). Dalam penggunaannya, subjek terkadang dibahasakan dengan substansi, pikiran, idea, ego, aku dan sebagainya. Pemikiran Rene Descartes misalnya, dapat dianggap sebagai representativ periode awal munculnya filsafat barat modern. Pada saat filsafat dan ilmu pengetahuan lepas dari penghambaan teologi, tapi masih meraba-raba dalam ketidakpastian metodenya, Descartes merasa terpanggil untuk menciptakan suatu metode yang dapat berlaku bagi semua ilmu pengetahuan. Dalam hal ini Descartes terpengaruh oleh filsafat Plato dan Aristoteles dalam mencari dasar kepastian epistemologi (pengetahuan).

Efek pemikiran Descartes ini melahirkan dua aliran besar dalam filsafat; Rasionalisme dan Empirisme. Rasionalisme mendasarkan pengetahuan pada rasio dan Empirisme pada pengalaman. Keduanya saling mengklaim sebagai sumber kebenaran. Namun pada akhirnya keduanya didamaikan oleh Imanuel Kant dengan aliran Kritisismenya. Sekalipun perdamaian Kant terhadap rasionalisme dan empirisme tidak benar-benar tuntas, tetapi ia telah berhasil menunjukkan adanya jalan terbuka untuk membangun suatu proses agar masing-masing pendirian tidak menjadi buta. Jalan ini di kemudian hari diperjelas oleh Edmund Husserl dengan fenomenologinya.

Pengaruh ajaran Kant dengan Aku-kritisnya, kemudian dikembangkan oleh Friedrich Hegel. Hegel tidak hanya sekedar menerangkan filsafat Kant, tapi berusaha menciptakan suatu sistem yang mencakup semua sistem filsafat, baik yang sudah ada maupun yang akan ada. Intinya, setiap bangunan filsafat dapat dijelaskan dari sistem filsafatnya. Hal ini dimulai dengan mempelajari sejarah dunia secara seksama untuk mencari dasar utama bagi segala permasalahan yang muncul. Hegel berkata; "perkembangan sejarah dunia tidak lain adalah wujud dari perjalanan Roh" (Tommy F. Awuy, 1995:18). Proses perjalanan Roh ini bersifat dialektis (gerak naik, gerak maju). Jadi , dalam konteks sejarah, perkembangan sejarah adalah perjalanan $\mathrm{Aku}$ Roh yang melegitimasikan diri.

Perjalanan totalitas subyek ini akhirnya berlanjut pada aliran fenomenologi dengan Edmund Husserl sebagai tokoh utamanya. Filsafat Husserl dibangun berdasarkan penyelidikan atas karya tokoh-tokoh pendahulunya, semisal Descartes dan Kant. Walaupun Husserl dianggap berhasil memecahkan kebuntuan filsafat Kant yang menyebutkan ada 
satu dunia yang tak terjangkau oleh rasio murni, sehingga rasio murni sertamerta berhenti pada dunia fenomena saja, Husserl tidak bisa terlepas dari peng-totalitasan subjek.

Berdasarkan hal ini terlihat kecenderungan filsafat barat selalu mengejar totalitas; artinya filsafat ingin membangun suatu keseluruhan yang berpangkal pada 'ego' sebagai pusatnya. Menurut Levinas, kecenderung filsafat barat untuk menyamaratakan yang berbeda dan yang berlainan dalam sebuah totalitas itu dengan istilah "sokratisme" (Suseno, 2000:94). Sokrates (sebagaimana kita mengenalnya melalui tulisan Plato) pada hakikatnya memandang orang lain sebagai "aku lain". Levinas menyatakan bahwa sejak Sokrates, filsafat barat selalu hendak mereduksikan yang banyak ke yang satu, dari yang berlainan kepada suatu kesamaan. Sokratisme filsafat Yunani menyamakan yang berlainan melalui prinsip-prinsip metafisis. Kant menggerogoti kemandirian "dunia luar" dengan fahamnya bahwa objek pengertian adalah hasil rekayasa kognitif subjek sendiri. Filsafat penyamaan ini mencapai puncaknya pada filsafat identitas Idealisme Jerman permulaan abad ke-19, dengan tokohnya Fichte, Schelling, dan Hegel. Contohnya adalah ketika pluralitas manusia direduksikan menjadi "momen" Roh Semesta dalam perjalanan pengembangan diri (Suseno, 2000:95).
Mengapa Levinas menentang filsafat identitas itu? Menurut Levinas, kalau semuanya itu identik, orang lain dalam keberlainannya, tidak terjamin. Kalau keberlainan orang lain mau dihilangkan, orang lain sendiri terancam. Secara filosofis, filsafat identitas menindas, meniadakan orang lain. Filsafat menjadi penindas dan totaliter. Sebagai seorang Yahudi, Levinas tahu betul apa artinya kalau orang, atau sekelompok orang, tidak diakui dalam keberlainan mereka.

Levinas ingin membangun sebuah filsafat dengan tidak berdasarkan kepada penyamaan seperti yang telah ada dalam filsafat Barat. Untuk melawan itu semua ia mengembangkan ketakberhinggaan. Totalitas itu didobrak oleh yang "tak berhingga". Dalam buku "Totalitas dan Tak Berhingga", Levinas mengatakan bahwa kecenderungan filsafat barat yang mengejar totalitas dan membangun keseluruhan yang berpangkal pada ego sebagai pusatnya, maka cara berfikir seperti ini disebut the philosophy of the same $(\mathrm{K}$. Bertens, 2006:319). Dalam filsafat modern titik tolak ini mendapat kedudukan kuat sejak pernyataan Descartes tentang cogito ergo sum (aku berfikir maka aku ada).

Totalitas dalam filsafat barat itu didobrak oleh Levinas dengan yang tak berhingga. Bila totalitas ini berpangkal pada ego, maka untuk melawannya, Levinas mengkedepankan yang takberhingga, yang tak lain adalah orang lain (autrui). Levinas mengatakan 
"Totalitas yang saya susun dengan seksama langsung pecah dalam perjumpaan dengan Orang lain. Adanya sesama manusia merupakan suatu fenomena yang sama sekali unik, yang tidak dapat diasalkan dari atau kepada sesuatu yang lain (Bertens, 2006:319). Orang lain itu bukan alter ego atau aku yang lain. Orang lain tidak dapat didekati dengan bertitik tolak dari "aku".

Dalam filsafat barat sampai sekarang, adanya sesama manusia belum pernah dipikirkan dengan semestinya. Adanya sesama manusia merupakan suatu fenomena yang unik yang tidak dapat diasalkan dari atau kepada sesuatu yang lain. Dengan orang lain tampak suatu eksterioritas, suatu transendensi. Orang lain tidak merupakan bagian dari suatu totalitas, ia tidak dapat dimasukkan dalam suatu keseluruhan. Ia selalu tinggal tersendiri, selalu mempertahankan otonomi. Untuk dapat menemuinya, menurut Levinas, saya harus keluar dari imanensi saya. Ia membuka suatu dimensi tak berhingga bagi saya. Jadi, orang lain itu bukan alter ego, bukan aku yang lain. Saya tidak dapat mendekati dia dengan bertitik tolak dari aku. Dia lain sama sekali. Orang lain adalah sipendatang, orang asing. Untuk itu saya harus mendatangi dia dan keluar dari ego saya karena ia membuka dimensi yang tak berhingga bagi saya (K. Bertens, 2006:320).

\section{Wajah sebagai Perwujudan Orang Lain}

Di atas telah diuraikan bahwa kecenderungan filsafat barat untuk menyamakan sesuatu (totalitas) dilawan oleh Levinas dengan yang tak berhingga. Yang tak berhingga itu adalah perwujudan dari orang lain. Menurut Levinas, dengan tak berhingga dimaksudkan di sini suatu realitas yang secara prinsip tidak mungkin dimasukkan ke dalam lingkup pengetahuan dan kemampuan saya. Yang tak berhingga itu adalah orang lain (K. Bertens, 2006:319).

Untuk

merumuskan pengalaman tersebut Levinas menciptakan istilah filosofis baru yaitu wajah. Analisis mengenai wajah (visage) merupakan salah satu pikiran pokok dari pemikiran Levinas. Wajah yang dimaksud Levinas bukan hal fisis atau empiris seperti keseluruhan yang terdiri dari hidung, bibir, dagu dan sebagainya. Tetapi yang dimaksudkannya adalah orang lain sebagai lain, orang lain menurut keberlainannya. Jadi, kualitas fisis yang bisa tampak pada wajah seperti tampan, muda, ceria dan sebagainya, tidak jadi hal penting. Wajah yang dimaksudkan Levinas adalah wajah telanjang; artinya wajah begitu saja, wajah dalam keadaan polos. Wajah yang mempunyai makna secara langsung, tanpa penengah, tanpa suatu konteks (K.Bertens, 2006:320).

Penampakan wajah merupakan suatu kejadian etis kata Levinas. Penampakan wajah menyapa dan meruntuhkan egoisme saya. Wajah menyapa saya, karena itu saya tidak 
boleh tak acuh saja. Ia mewajibkan saya agar saya mempraktekkan kebaikan dan keadilan. Wajah saya diinterpelasi dari atas dan dipanggil untuk bertanggung jawab (K. Bertens, 2006:321). Kewajiban etis yang timbul dari penampakan wajah orang lain harus dianggap asimetris. Artinya, apa yang saya berikan pada orang lain tidak boleh saya tuntut dari dia. Saya boleh memberikan kebaikan bagi sesama tetapi saya tidak berhak untuk membuat dia menjadi keuntungan bagi saya. Jadi relasi saya dengan orang lain tidak boleh didasarkan atas balas jasa.

Pemikiran yang membuka diri bagi dimensi tak berhingga yang tampak dengan adanya "wajah" atau "yang lain", oleh Levinas disebut metafisika. Karena penampakan wajah merupakan suatu kejadian etis maka menurut kodratnya, metafisika harus juga bersifat etis. Jadi, menurut Levinas, metafisika dan etika tidak dapat dipisahkan (K. Bertens, 2006:322).

Salah satu kritik Levinas pada filsafat modern adalah titk tolak filsafat yang berpusat pada ego seperti ajaran Descartes: cogito ergo sum. Bagi Levinas, bukan refleksi tentang diri saya yang menyingkapkan aku yang sejati, melainkan kejutan yang dialami ketika berhadapan dengan orang lain. Dengan berhadapan dengan orang lain, saya barulah menjadi saya, saya menemukan identitas saya. Dengan bertemu dengan orang lain saya menyadari keunikan saya. Orang lain membuat saya menjawab; "inilah aku"
(Suseno, 2000:100). Berdasar ini, kata Levinas, ajaran Descartes tentang cogito ergo sum (aku berfikir maka aku ada) seharusnya diganti menjadi respondeo ergo sum (saya bertanggung jawab maka saya ada) (K. Bertens, 2006:327).

\section{Orang Lain Menciptakan Tanggung Jawab}

Berdasarkan uraian di atas
dapat dipahami bahwa dalam
perjumpaan Subjek dengan Objek, yang tidak lain adalah perwujudan dari orang lain, membuat Subjek menjadi bertanggung jawab karena orang lain ini. Dalam perjumpaan ini setidaknya ada tiga hal yang patut digarisbawahi. Pertama, saya sebagai yang bertanggung jawab. Kedua, orang lain atasnya saya bertanggung jawab. Ketiga, ketakberhinggaan terhadapnya saya harus memberi pertanggungjawaban itu.

Levinas sebenarnya ingin menunjukkan bahwa pengalaman paling dasariah manusia hanya dapat dimengerti kalau sesama, orang lain itu, dipahami sebagai titipan dari Yang Tak Terhingga di atasnya kita bertanggung jawab. Ini berarti dalam pandangan filsafatnya Levinas mengantarkan ke pintu Tuhan dengan suatu titik tolak dari tanggung jawab kepada seorang manusia. Singkatnya, melalui wajah orang lain mengharuskan kita bertanggung jawab, melalui tanggung jawab kita bergerak menuju Tuhan. Jadi, dengan tanggung jawab kita dapat mengenal Tuhan 


\section{KESIMPULAN}

Berdasarkan uraian di atas dapat disimpulkan bahwa sumbangan terbesar yang diberikan oleh levinas adalah bahwa ia telah berusaha mengangkat posisi 'yang lain' dalam filsafat. 'Yang lain' ini selama ini terkesan diabaikan oleh filsafat (terutama filsafat barat yang lebih banyak berkutat pada 'Aku'). Di samping itu levinas memperlihatkan bahwa relasi antar sesama seharusnya didasari oleh suatu tanggungjawab. Tanggung jawab ini menjadi dasar bagi pertanggungjawaban kepada Tuhan.

Pemikiran Levinas ini juga menggugah kesadaran bahwa sangat diperlukan keterbukaan yang komunikatif dan melanjutkannya, bukan sekedar kewajiban etis semata. Ini dapat menjadi dasar bagi manusia modern yang seringkali terjebak dalam arus globalisasi yang menggiring pada sikap individualisme dan egoisme mutlak. Di sana manusia akan menemukan kehancuran karena tidak menghargai manusia lainnya.

\section{DAFTAR KEPUSTAKAAN}

Bagus, Lorens, Kamus Filsafat, (Jakarta: Gramedia), 1996.

Bertens, K., Ringkasan Sejarah Filsafat, (Yogyakarta: Kanisius), 1975.

Bertens, K., Filsafat Barat Kontemporer Prancis, (Jakarta: Gramedia), 2006.

Hadiwijono, Harun, Sari Sejarah Filsafat Barat 2, (Yogyakarta: Kanisius), 1980.

Magnis-Suseno, Franz, 12 Tokoh Etika abad 20, (Yogyakarta: Kanisius), 2000 .

Tommy F. Awuy, "Problem Ego dalam Filsafat Modern dan Postmodern" dalam Jurnal Filsafat, (Jakarta: Lembaga Studi Filsafat), 1995. 